\title{
The Effects of Corrective Feedback on Chinese Learners' Writing Accuracy: A Quantitative Analysis in an EFL Context
}

\author{
Xin Wang ${ }^{1, *}$ \\ ${ }^{1}$ College of Education, Northern Arizona University, AZ, USA \\ *Correspondence: College of Education, Northern Arizona University, AZ, USA. E-mail: xw37@nau.edu
}

Received: February 13, 2017

Accepted: February 21, 2017 Online Published: April 25, 2017

doi:10.5430/wje.v7n2p74

URL: https://doi.org/10.5430/wje.v7n2p74

\begin{abstract}
Scholars debate whether corrective feedback contributes to improving L2 learners' grammatical accuracy in writing performance. Some researchers take a stance on the ineffectiveness of corrective feedback based on the impracticality of providing detailed corrective feedback for all L2 learners and detached grammar instruction in language classrooms. On the other hand, many researchers promote the efficacy and significance of the role played by corrective feedback in the process of L2 writing. This research employs a quasi-experimental design and examines two major issues: (1) the extent to which CF facilitates or improves students' writing accuracy; (2) students' expectations and preferences for CF. The research consists of 105 college level EFL learners from three intact classes in an Eastern Chinese University. One class was assigned to the control group which only received comments on content of their writing. The other two classes were then assigned to each of the two experimental groups which received indirect or direct CF. Data collection includes student text/error analysis, treatments (i.e., provision of corrective feedback), examination of tests (i.e., pretest, posttest and delayed posttest), and questionnaires. Within a research period of ten weeks, this study did not reveal statistically significant group differences between the two CF groups and the control group on overall error reduction. However, students believed CF was important and beneficial, although there is contradiction between what the students believed and their teachers' actual practices in the classroom. Pedagogical recommendations for EFL teachers are also discussed.
\end{abstract}

Keywords: $E F L$; academic writing accuracy; indirect $C F$; direct $C F$; learner attitudes

\section{Introduction}

Corrective feedback (CF) often refers to negative evidence in second language acquisition (SLA) and sometimes is used interchangeably with error correction/grammar correction by researchers. Russell and Spada (2006) defined corrective feedback as "any feedback provided to a learner, from any source, that contains evidence of learner errors of language form." (p. 134) Corrective feedback, in this case, does not refer to any feedback that is not related to grammatical forms.

One of the top responsibilities of language teachers is to provide feedback for student papers so that second language (L2) learners can see whether they are good writers or whether the pedagogical practices meet students' expectations of instruction. Corrective feedback provides critical information to inform students about their writing performance and transform students to critical and proficient L2 writers. Despite long debates since the 1970s, the most productive approach to providing corrective feedback in L2 writing has yet been precisely developed (Ferris, 2010), even though researchers and teachers have tried to "justify their faith in written corrective feedback with hard evidence" (Ellis et al., 2008, p.353).

According to Ferris (2010), because of the historical and theoretical trends, empirical research on corrective feedback in L2 writing was scarce before the mid-1990s. Influenced by Krashen's SLA theory (1981, 1982, \&1985), corrective feedback was not valued then in writing instruction. After the 1990s, more research started addressing language issues in L2 writing, advocating the idea that error correction should be contextualized within the writing process, prioritized to focus on the most frequent and serious errors and should pay attention to individual learners' needs in writing.

Scholars debate whether corrective feedback contributes to improving L2 learners' grammatical accuracy in writing 
performance. Based on the impracticality of providing detailed corrective feedback for all L2 learners and detached grammar instruction in language classrooms (e.g., some Intensive English Programs in the U.S. do not offer grammar instruction for intermediate and higher proficiency level ESL learners), some researchers take a stance on the ineffectiveness of corrective feedback (Robb, et al., 1986; Kepner, 1991; Bruton, 2009; Truscott, 1996, 1999, 2004 , 2007; Truscott \& Hsu, 2008). Kepner (1991) found no significant effects of feedback on language forms in L2 college students' writing, and concluded that corrective feedback is ineffective for developing learners' grammatical accuracy in writing. Truscott (1996) denied the relationship between the usefulness of error feedback and L2 learning and claimed that error correction is ineffective and harmful in improving students' L2 learning. He even made a strong argument that error correction "should be abandoned" (p. 328)

On the other side, some researchers found corrective feedback to be effective for written errors. Researchers who advocate grammar correction also emphasize strategy training in order to develop L2 learners' ability of being autonomous editors of their own writing (Bitchener \& Knoch, 2009, 2010; Ferris, 2010; Van Beunnigen, De Jong, \& Kuiken, 2012; Vyatkina, 2011). Russell and Spada (2006) in a meta-analysis provided support for the effectiveness of corrective feedback in general for L2 grammar learning. The meta-analysis showed a medium to large effect size for the majority of the primary studies that investigated the effects of corrective feedback on written performance and confirmed a positive effect for corrective feedback on L2 acquisition. As shown by the research that demonstrates the effectiveness of corrective feedback, the extent to which type of corrective feedback may play a better role in improving L2 learners' accuracy of writing becomes an interesting issue to consider.

As arguments for and against corrective feedback are investigated in SLA literature, a growing body of empirical research (Bitchener\&Ferris, 2011; Ferris, et al., 2013; Jernigan \& Mihai, 2008; Lee, 2005; Lee, 2008; McMartin-Miller, 2014) explores another crucial issue: students' and teachers' perceptions and preferences towards $\mathrm{CF}$ in L2 writing. Previous research suggests that, for both ESL and EFL learners, beliefs about error correction as an effective instructional technique differ substantially from the belief and practices of their teachers. For example, students prefer to have all their errors corrected, while teachers only address the errors when communication is affected in writing (Jernigan \& Mihai, 2008). Therefore, attention needs to be paid to how corrective feedback is perceived by $\mathrm{L} 2$ learners and teachers.

Controversies concerning corrective feedback are ongoing and inconclusive. Scholars have yet to address whether corrective feedback is effective in helping learners to eliminate errors in new pieces of writing. In addition, though abundant literature examines how teachers should balance different types of corrective feedback, learners' perspectives are also an ignored area in investigations of the effectiveness of CF (Ferris \& Roberts, 2001; Mustafa, 2012). Another frequently mentioned issue in previous research is that few studies are empirically conducted on a comprehensive identification of all the error types in EFL learners' production of writing. Therefore, the above-mentioned possibilities are the major factors that motivate this investigation.

\section{Literature Review}

\subsection{Arguments against Corrective Feedback}

A considerable number of investigations center on the subjects of corrective feedback in L2 and pose controversies among L2 researchers and language teachers. Based on previous studies, some researchers take a position regarding this issue and argue that corrective feedback does not facilitate L2 learners' language performance. One of the well-known position papers was published by Truscott (1996), which inspired increased interest in the topic of corrective feedback on the part of researchers. Truscott (1996) denied the relationship between the usefulness of error feedback and L2 learning and took a strong position that grammar correction has no place in L2 writing and should be abandoned.

Truscott (1996) considered from both theoretical and practical aspects to explain why grammar correction cannot work. From the theoretical perspective (i.e., orders of acquisition, interlanguage, and the role of L2 intuition vs. metalinguistic knowledge), Truscott pointed out two specific theoretical problems of grammar correction. First, grammar correction only deals with the superficial part of grammar and ignores the underlying process of language development. Truscott argued that many teachers intuitively assume that students can understand and remember the corrections and are able to use them properly in their future writing. However, becoming proficient in English is a complex and long process. Acquisition of grammar is a gradual process rather than relying on transfer of knowledge or a sudden discovery based on teaches' intuitive viewpoint of learning. It involves inherent and consistent order or sequence of the acquisition of certain grammatical structures. Therefore, teachable moments and developmental sequences need to be taken into account. 
Another theoretical problem is described as pseudolearning. It means that learners can have acquired good knowledge of the target language but are not able to use it. Much research shows that the ability to correct errors is different from the ability to state the rules of grammar correction. Sometimes, students are not willing to make corrections they receive or may fully understand the corrections but still make errors in their writings.

Truscott (1996) also doubted the value of grammar correction based on a practical consideration. First, teachers may fail to notice the errors, especially for teachers who are not native speakers of the target language. Even if teachers realize and correct the errors, they may not have a good understanding of the correct use of grammar due to lack of knowledge and lack of time. The quality of the corrections becomes a problem in this case. Also, teachers are not consistent and systematic in their corrections, especially when they are dealing with many students and with many different errors. Another problem is that even if teachers can give good explanations and students can deal with the errors, they both may not be motivated to do so, especially if they need to deal with many of them. Students do not pay attention to corrections and are not motivated to think about the correction in future writing. Many students do not seriously deal with corrections because they see it as a form of punishment.

In addition, researchers and scholars (Truscott, 1996, 1999) stated that grammar correction has harmful effects on learners themselves. Students find corrections discouraging because they do not like to be corrected repeatedly all over their writing. Many students who do not receive corrections tend to have a more positive attitude toward writing. Research also shows that because of the positive attitudes uncorrected students develop toward writing, they tend to write more and show a superior grasp of grammar, such as sentence boundaries. On the other side, the corrected students tend to simplify their writing in order to avoid being corrected. They do not learn as much as uncorrected students because of the negative attitude toward learning. Another reason researchers believes correction is harmful is because of its time-consuming nature. Focusing on grammar correction distracts students and teachers' attention from other, more important, "high level" aspects of writing, such as organization and content of writing.

\subsection{Arguments for Corrective Feedback}

Regarding the importance of corrective feedback in L2 learning, a growing number of L2 researchers (Lee, 2005; Bitchner, 2008; Bitchnener and Knoch, 2008, 2010) argue in favor of the positive contribution corrective feedback makes to L2 learning, especially for a consistent learning process. Extensive research makes it clear that corrective feedback should be a part of the instruction in language classroom because of its facilitative role in second language acquisition (SLA).

Ferris is the most prominent advocate of grammar correction. Ferris (1999) evaluated Truscott's viewpoints on the ineffectiveness of grammar corrections. She claimed Truscott's arguments on grammar correction are premature and overly strong. Ferris believed that error correction is a great concern in L2 writing and a controversial issue for researchers and classroom teachers. Her own teaching experience and extensive empirical research tells that many students benefit from corrective feedback, and have even made great improvements in their accuracy of writing. According to Ferris (1999), corrective feedback at least results in short term learning outcomes and possibly an indicator of long term improvements as well. Ferris then provided the reasons that addressed the need to continue the practice of grammar correction. First, students themselves are concerned about accuracy and expect to receive feedback from teachers. Many grading rubrics of writing explicitly outline that poor use of grammar prevents students from achieving high scores in writing proficiency examinations. Thus, the absence of grammar feedback can frustrate students, and thus negatively affect students' motivation and confidence in their writing. Second, some instructors in college are not tolerant of typical ESL errors, because they feel the errors would affect the overall evaluations of students' papers. Third, appropriate corrective feedback can enhance learners' metalinguistic awareness, which is crucial for students to be capable to self-edit their own writing (Ferris, 1999, 2004, 2010).

With regard to the significance of corrective feedback, other researchers also point out that L2 learners who receive error correction produce more accurate texts than those who do not. From the long-term perspective, with repeated improvements in accuracy, corrective feedback leads to the development of L2 learners' overall language proficiency overtime. Especially for adult L2 learners, explicit error feedback greatly decreases the likelihood of fossilization during their L2 learning (Kang\&Han, 2015; Polio, 2012, Shintani, Ellis,\& Susuki, 2014). Fossilization is a phenomenon that occurs during second language acquisition, in which L2 learners tend to formulate their own rules in language production. The rules are influenced either by their first language (L1) structure or their correct or incorrect perception of L2 structure. If the rules turn into a permanent feature, this phenomenon is called fossilization, which hinders students' L2 acquisition and learning. Thus, without corrective feedback, L2 learners have difficulty realizing why and how the errors happened and to further develop an advanced skill of language. 


\subsection{Types of Corrective Feedback}

Among the extensive research that explores the effectiveness of corrective feedback, the question of which type of corrective feedback prompts more improvements in L2 learners' language performance has been an interesting issue to consider. A rich literature has investigated the effects of different types of corrective feedback on L2 learning (Chandler, 2003; Sheen, Wirght, \& Moldawa, 2009; Van Beuningen, De Jong, \& Kuiken, 2012). Some evidence shows that explicit and direct corrective feedback is more effective in eliciting learners' immediate revisions and subsequent correct use, while some theoretical arguments support implicit and indirect corrective feedback because this is more related to focus on meaning. However, few conclusions tell us which one is more effective for L2 acquisition.

Many researchers support the use of indirect CF because it is claimed to encourage students' analytic reflection to guide their own learning, engagement in the problem-solving process, and processing of the feedback they receive (Chandler, 2003; Ferris \& Robert, 2001; Shintani, Ellis, \&Suzuki, 2014). Thus, indirect feedback brings benefits to a long-term improvement in students' L2 learning. In one of the few longitudinal classroom-based studies investigating teachers' CF strategies and student progress over time, it was found that while direct correction led to a higher level of correction in short-term revision, greater gains were found in long-term written accuracy as a result of indirect feedback. For direct feedback, however, teachers may inappropriately interpret students' intention and provide the wrong corrections for students.

Nevertheless, other researchers (Bitchener and Knoch, 2008, 2010) questioned the effectiveness of indirect feedback and are in favor of the direct correction of errors because direct approach reduces the confusion if students do not understand what the error means. Direct feedback requires minimal cognitive processing, helps students deal with more difficult and complicated errors, and obtain an immediate improvement in their L2. Thus, direct feedback is particularly appropriate for beginning language learners (Lee, 2003). However, in light of indirect feedback, only identifying errors may cause students' confusion and difficulties in comprehending and decoding the errors.

\subsection{Perceptions of Corrective Feedback in L2 Learning}

Linguistics errors are pervasive in L2 writing, and may cause different degrees of irritation or even communication breakdown to teachers or other readers. Thus, student errors in writing becomes a major concern for students and providing corrective feedback for student writing has been an essential practice for teachers. The following exploratory studies examined the particular beliefs of students and teachers regarding the role of corrective feedback and students' reactions to teachers' feedback in language learning.

Negative perceptions. Some research in SLA has suggested that students who have not received error correction hold more positive attitudes towards writing because students may be frustrated when errors are marked repeatedly, though they accept the fact that making errors is part of the learning process (Truscott, 1996; Truscott and Hsu, 2008). At this point, students are inclined to avoid using complex sentence structures or advanced vocabularies with the purpose of avoiding corrections. There exists a great possibility that students who have received numerous corrections do not perform as well as those with only few amendments because their pessimistic feelings toward learning develop over time.

Individuals may argue that if teachers correct a few important errors continuously, it would be easy for students to take care of the corrections and improve for the future. However, this is not applicable for teachers because they have to look at a large number of students' writings, which requires patience and consumes time. Besides, under certain conditions in which students will repeat the errors that they made over a long time, teachers would consider students sluggish and inattentive. Both the situations can leave room for teachers to possibly overlook students' errors and simply conclude that error correction is ineffective (Bruton, 2009; Lee, 2003; Truscott \& Hsu, 2008).

Furthermore, as discussed in Lee (2003), because of insufficient linguistic knowledge, some unconfident teachers express their concerns in providing appropriate error corrections for students. Even though language teachers are able to easily recognize students' grammatical errors, some teachers cannot fully and successfully explain them, which causes teachers' irritation and anxiety in dealing with the problems. Accordingly, this lack of confidence may result in the inconsistency of teachers' error correction practices with their beliefs and insufficient preparation to help students with their self-editing skills in language production.

Positive perceptions. The following studies show the researchers, teachers and students who believe that corrective feedback is necessary in any language classroom. In particular, it is helpful in enhancing L2 learning in adults. In evaluating ESL students' attitudes toward corrective feedback in a college-level English writing class, Leki's (1991) research indicated that ESL students were concerned with their written errors and believed that high quality writing 
should be error-free. They expected teachers to have all their errors corrected in their writing. Schulz's (2001) study also investigated students' and teachers' perceptions regarding the role of corrective feedback in adult L2 learning regarding the effectiveness of corrective feedback in American and non-American learning contexts. Results revealed that students in Colombia and the U.S. would like to be corrected and felt teachers should correct their errors in speaking and writing. Teachers in both cultures showed little disagreement as well, and agreed that students' errors in the target language should be corrected.

As Ferris (2004) stated, studies concentrating on L2 learners' attitudes and opinions about error feedback are very consistent in demonstrating that L2 student writers show a general preference and strong expectation for error correction. They regard error feedback from their teachers as an essential contributor to the success of their language production. Since L2 learners not only care about but also frequently struggle with linguistic accuracy, L2 learners believe in the importance and benefit of teachers pointing out the errors for the purpose of eliminating the possibility of making grammatical errors during their L2 development. Conversely, the lack of feedback from teachers can be harmful due to students' strong belief about this issue. As Ferris (1999) claimed about L2 writing:

"... the absence of any form of grammar feedback could frustrate students to the point that it might interfere with their motivation and confidence in the writing class, particularly when grading rubrics and writing proficiency examination results tell them that their language errors could prevent them from achieving their educational and professional goals." (p.8)

Ferris (1999) also argued that students highly value teachers' comments on grammar, as feedback triggers them to make effective revisions, which further affects their writing performance. Similarly, Hyland (2003) conducted another study that examined students' perception of the effect of error feedback on their L2 writing product and revision strategies. Subjects who engaged in Hyland's research varied in different levels of English proficiency and backgrounds. The researcher pointed out that an affirmative relationship exists between error feedback and the quality of students' writing. Students' engagement with form-focused feedback motivated them to develop their self-revision skills in writing and eventually helped them make good progress in the problems that are addressed in the feedback. Though error feedback may not have an immediate effect, students hold a firm belief that continual feedback from teachers would ultimately benefit them. Without feedback, students would be more likely to fail to notice the errors.

Research also reveals that since accuracy is one of the fundamental criteria for the assessment of academic performance, some language teachers, especially at the college level, are less or even not at all tolerant of "typical" ESL errors compared to the "typical" errors committed by native speakers, and therefore demand linguistically error-free academic performance from L2 writers (Ferris, 1999). Hence, it seems that a stigma exists in academia in terms of students' inaccurate language performance. For example, teachers feel linguistic errors can adversely affect their overall evaluation of students' papers.

\subsection{EFL Context in China}

Today, English is extensively used in many provinces of China. By 2016, China had the largest English speaking population in the world. Concurrently, English instruction in China has becomes more intensively studied. Various teaching approaches and pedagogies have been investigated at different levels of schools. In 2002, the Chinese Ministry of Education announced that English would become a required course starting from the third grade (Liu \& Braine, 2005). Since then, English has become an important part of the curriculum, which covers listening, speaking, reading, writing and grammar; Chinese English learners start practicing and studying English skills intensively in middle school, and English even has a decisive role for students in the college entrance exam (i.e., "Gao Kao" in Chinese), which is the only criterion for admission to universities in China.

In China, formal instruction and grammatical accuracy are emphasized in English teaching and learning, and the traditional teaching approach still prevails, although efforts have been made to move away from it. Most of the time, L2 writing in English has primarily been seen as a matter of filling in blanks, following pattern drills and producing linguistically controlled writing due to the test-oriented feature of English instruction. This pattern of learning leads students to a low English speaking and writing ability but helps students obtain high scores in reading and listening. Research indicates that there is a gap between Chinese literacy instruction and EFL language instruction due to the reality of communicative purpose (Wang, 2011). 


\section{Methodology}

\subsection{Research Questions}

1. Does accuracy improve as a result of the provision of corrective feedback (CF) in L2 writing?

2. What type of CF will better help facilitate students' L2 writing accuracy (e.g. indirect CF and direct CF)?

3. What are Chinese students' expectations and preferences for the feedback on writing?

\subsection{Participants}

The population of the research consists of 105 college level EFL learners in an Eastern Chinese University. Their ages ranged from 18 to 20 . The participants were already randomly assigned into three classes when they entered college after they took the Chinese College Entrance Examination (also called "Gao Kao"). One class was assigned to the control group which only received comments on content of their writing from the researcher. The other two classes were then assigned to each of the two experimental groups which received different types of corrective feedback: indirect or direct CF. All the participants were English majors with the same English proficiency based on the grades they received on the Chinese College Entrance Examination. They had a common L1 (i.e. Chinese) background and years of previous English learning experiences.

\subsection{Data Collection and Analysis for RQ1 and RQ2}

105 essays were examined for all types of grammatical errors that were committed by the EFL learners, such as subject-verb agreement, article, tense, verb, preposition, parts of speech, etc. 105 participants from three classes were divided into one control group and two comparison groups. Therefore, each group had 35 students. Over a research period of two months, the researcher collected three different writing texts from each student, which were under timed conditions: a diagnostic essay in Week 1 (i.e., the pretest), a midterm examination in Week 5 (i.e., the posttest) and a final examination essay in Week 10 (i.e., the delayed posttest). Task variables are presented below in Table 1.

Table 1. Task Variables of Pretest, Posttest and Delayed Posttest

\begin{tabular}{ll}
\hline Pretest (Week 1) & Argumentative essay \\
Prompt: Does technology affect our lives? How? Please provide at & 300 words in length on average expected \\
least three reasons for your argument. & $60-90$ minutes \\
\hline Posttest (Week 5) & Argumentative essay \\
Prompt: Which is good for college students? Please provide at & $300-400$ words in length on average expected \\
least three reasons for your argument. & $60-90$ minutes (including planning and writing) \\
\hline Delayed-posttest (Week 9) & Argumentative essay \\
Prompt: Do colleges put too much stock in standardized test & 400 words in length on average expected \\
scores? Please provide at least three reasons for your argument. & $60-90$ minutes (including planning and writing) \\
\hline
\end{tabular}

During the examination of student errors in terms of accuracy, the syntactic structures and certain factors that the criteria would consider are shown in Table 2.

Table 2. Syntactic Structures for Grammar Accuracy

Grammar accuracy

- $\quad$ Subject-verb agreement: S-V-O structure

- Verb tense and aspect (present, past, progressive, present perfect)

- Plural vs. Singular

- Verbs (modal verb, main verb, copula verb)

- Articles (definite vs. indefinite)

- Prepositions

- Pronouns (possessive, reflexive, demonstrative, relative pronoun)

- Possessive

- Existential there

- Comparatives

- Parts of speech

- Word order (mistakes may occur in more complex structures when the subject gets separated from the verb) 
After identifying and categorizing all types of errors, Group One students received indirect corrective feedback; indirect feedback occurred when the researcher indicated that an error existed by circling or underlining the errors in student text but did not provide direct correction. This left the errors for students to correct them. For example (from students' pretest writing):

(1) The invention of computers dramatically increases work efficiency and help compete many difficult tasks that were impossible in the past. ( _ _ indicates a wrong word form)

(2) Thanks to $\sqrt{ }$ development of science and technology, the society has enjoyed continuous prosperity and more convenience. ( $\sqrt{ }$ means a missing word)

Group Two received direct CF, which took the form of full and explicit error correction above the underlined errors. For example (from students' pretest writing):

helps

(3) The invention of computers dramatically increases work efficiency and help compete many difficult tasks that were impossible in the past.

the

(4) Thanks to $\sqrt{ }$ development of science and technology, the society has enjoyed continuous prosperity and more convenience.

Group Three received zero error correction but feedback on the content of their writing. Examples of feedback for Group Two in pretest writing are shown below:

(5) You did a good job presenting your ideas on one side of the argument. I enjoyed reading your writing, which was very interesting. You were good at using transition words. This made your writing go smoothly.

(6) Good job with the discussion about the positive effect of technology. Your ideas flew very well and very straightforward. I hope to see your progress on the next writing.

The researcher then returned the feedback to students three days after students competed their first and second writing task. The student participants were given four weeks outside of class to revise their writing, and make any changes or corrections in response to the errors. The posttest was conducted one month after students received feedback from the researcher for their first writing task (i.e., pretest), and a delayed posttest was administrated at the last week, that is, four weeks after students received feedback from the researcher for their second writing task (i.e., posttest).

Preliminary analysis of the data involved identification and classification of different errors committed by the EFL learners from the control and experimental groups. Quantitative data were elicited from the pretest, the posttest, and the delayed posttest to discover whether the two different types of corrective feedback positively affect students' L2 writing outcome, and to compare the longitudinal effects caused by the two types of corrective feedback and the feedback on content, which were measured on the quantitative variable: accuracy performance in student L2 writing. Descriptive statistics, such as the mean score (M) and standard deviation (SD), were computed. In addition, in order to compare across texts of different lengths, the distribution of errors in each student text was distinguished and analyzed by the normed frequencies (Biber, et al. 1999), which were reported as the rate of occurrences per 1000 words in this study.

Moreover, Paired Sampled T-Test was conducted to examine the time effect of different types of feedback on improving students' writing accuracy within the three groups. A one-way ANOVA was also chosen to determine if there were statistically significant differences among the three groups.

\subsection{Data Collection and Analysis for RQ3}

All student participants in the three groups were asked to complete questionnaires about their writing and language learning backgrounds (e.g., information of students' formal English instruction and schooling in China) before they started the first writing task (the pretest) (see Appendix A). Then, students were required to fill out another questionnaire after the delayed posttest, which compared the different types of teacher feedback. Students were asked about the questions that were specifically related to the effectiveness of corrective feedback (see Appendix B).

Quantitative data from questionnaires were analyzed using SPSS including both descriptive (M and SD) and inferential statistics (i.e., Correlation Coefficient and one-way ANOVA) to analyze the multiple-choice items and to 
discover whether the three different types of feedback positively affect EFL learners' L2 writing outcome and their perceptions. For example, the Mean and Standard Deviation for each item in the questionnaires were calculated, which told us how much variability is in students' responses; the correlation coefficient was reported to see if there was any relationship existing between students' attitudes and their accuracy performance. A one-way ANOVA was conducted as well to reveal if there was any significant difference in students' responses across the three groups. 3.

\section{Results}

\subsection{RQ1\&RQ2: Overall Effectiveness of CF in Relation to Students' Improvement in L2 Writing Accuracy.}

Table 3 displays the means and standard deviations of the normed frequencies in the pretest, posttest, and delayed posttest for the three groups, which helped control for the effect of text length in the tests. Figure 1 is a visual representation of the normed frequencies of error rates across the three treatments in the three groups. As shown, the two CF groups had a greater degree of error reduction in general than the control group.

Table 3. Mean and Standard Deviation of Normed Frequencies for Corrective Feedback by Group in the Pretest, Posttest, and Delayed-posttest

\begin{tabular}{cccccccc}
\hline Group $^{\mathrm{a}}$ & \multicolumn{2}{c}{ Pretest } & \multicolumn{2}{c}{ Posttest } & \multicolumn{2}{c}{ Delayed posttest } & $\mathrm{N}$ \\
\cline { 2 - 8 } & $\mathrm{M}$ & $\mathrm{S}$ & $\mathrm{M}$ & $\mathrm{S}$ & $\mathrm{M}$ & \multicolumn{1}{c}{$\mathrm{S}$} & \\
\hline ICF & 16.5 & 10.98 & 7.3 & 7.35 & 6.1 & 5.91 & 35 \\
FC & 11.0 & 13.45 & 8.8 & 10.30 & 5.6 & 10.76 & 35 \\
DCF & 18.2 & 14.08 & 6.0 & 6.44 & 6.5 & 7.84 & 35 \\
Total & 15.2 & 13.15 & 7.4 & 8.20 & 6.0 & 8.34 & 105 \\
\hline
\end{tabular}

Note. ${ }^{\text {a }}$ ICF $=$ Indirect Corrective Feedback Group; FC =Feedback on Content Group; DCF = Direct Corrective Feedback Group

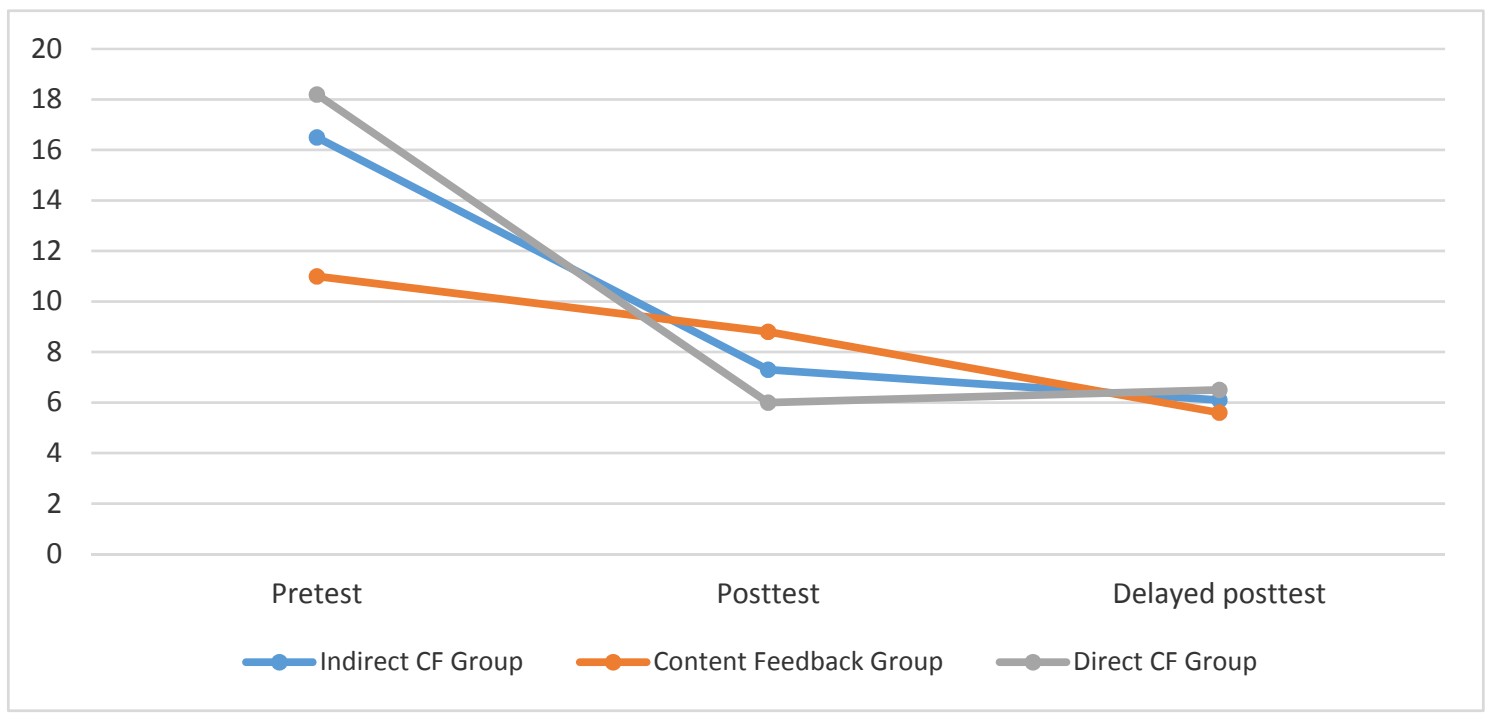

Figure 1. Mean of Normed Frequencies of Error Rates of the Three Groups in the Three Tests

Paired Samples T-Tests were conducted to see if each group had statistically significant changes regarding the normed frequencies of errors rates students produced from the pretest to posttest, from the posttest to delayed posttest as well as from the pretest to delayed posttest. Table 4, 5, and 6 below present statistics for the Indirect CF, the Direct CF, and the control (FC) group.

As shown in Table 4, a significant decrease was found in the indirect CF group from the pretest to posttest $(\mathrm{t}=4.08$, $34 \mathrm{df}, \mathrm{p}=.00, \mathrm{p}<.05)$ with a medium effect size (Cohen's $\mathrm{d}=.44)$ and from the pretest to delayed posttest $(\mathrm{t}=4.35$, $34 \mathrm{df}, \mathrm{p}=.00, \mathrm{p}<.05$ ) with a medium to large effect size (Cohen's $\mathrm{d}=.51$ ), indicating a significant effect of time on 
indirect CF in students' performance on writing.

Table 4. Paired Samples T-Test for Corrective Feedback in Indirect CF Group in the Pretest, Posttest, and Delayed-posttest $(\mathrm{n}=35)^{\text {a }}$

\begin{tabular}{|c|c|c|c|c|c|c|c|c|}
\hline \multirow[t]{2}{*}{ Treatment ${ }^{\mathrm{b}}$} & \multirow[t]{2}{*}{$M$} & \multirow[t]{2}{*}{$S D$} & \multicolumn{2}{|c|}{$\begin{array}{l}\text { 95\% Confidence Interval of the } \\
\text { Difference }\end{array}$} & \multirow[t]{2}{*}{$t$} & \multirow[t]{2}{*}{$d f$} & \multirow[t]{2}{*}{$\begin{array}{c}\text { Sig. } \\
\text { (2-tailed) }\end{array}$} & \multirow[t]{2}{*}{ Cohen's a } \\
\hline & & & Lower & Upper & & & & \\
\hline $1-2$ & 9.18 & 13.29 & 4.61 & 13.74 & $4.08^{*}$ & 34 & $.00 *$ & .44 \\
\hline $2-3$ & 1.2 & 8.78 & -1.81 & 4.22 & .81 & 34 & .42 & .09 \\
\hline $1-3$ & 10.38 & 14.13 & 5.53 & 15.23 & $4.35^{*}$ & 34 & $.00 *$ & .51 \\
\hline
\end{tabular}

Note. ${ }^{\text {a. }}$ statistics are calculated based on normed frequencies (number of errors/ total number of words * 1000) of errors. ${ }^{*} p<.05$; ${ }^{\mathrm{b}}$ : Treatment $1=$ pretest, Treatment $2=$ posttest, Treatment $3=$ delayed posttest.

As shown in Table 5, as the same to the indirect CF group, a decrease in the direct $\mathrm{CF}$ group turned out to be significant from the pretest to posttest $(\mathrm{t}=6.06,34 \mathrm{df}, \mathrm{p}=.00, \mathrm{p}<.05)$ with a medium effect size (Cohen's $\mathrm{d}=.49)$ and from the posttest to delayed posttest $(\mathrm{t}=4.98,34 \mathrm{df}, \mathrm{p}=.00, \mathrm{p}<.05)$ with a medium effect size (Cohen's $\mathrm{d}$ $=.46$ ), indicating that there was a significant effect of time on direct $\mathrm{CF}$ for students' performance on writing.

Table 5. Paired Samples T-Test for Corrective Feedback in Direct CF Group in the Pretest, Posttest, and Delayed-posttest $(\mathrm{n}=35)^{\mathrm{a}}$

\begin{tabular}{ccccccccc}
\hline Treatment $\mathrm{t}^{\mathrm{b}}$ & $M$ & $S D$ & \multicolumn{9}{c}{$\begin{array}{c}95 \% \text { Confidence Interval of the } \\
\text { Difference }\end{array}$} & $t$ & $d f$ & $\begin{array}{c}\text { Sig. } \\
\text { (2-tailed) }\end{array}$ & Cohen's d \\
\cline { 3 - 9 } & \multicolumn{7}{c}{ Lower } & Upper \\
\hline $1-2$ & 12.22 & 11.93 & 8.12 & 16.31 & $6.06^{*}$ & 34 & $.00^{*}$ & $\mathbf{. 4 9}$ \\
$2-3$ & -.48 & 8.78 & -3.50 & 2.53 & -.33 & 34 & .75 & -.03 \\
$1-3$ & 11.73 & 13.95 & 6.94 & 16.52 & $4.98^{*}$ & 34 & $.00^{*}$ & $\mathbf{. 4 6}$ \\
\hline
\end{tabular}

Note. ${ }^{\text {a. }} \quad$ statistics are calculated based on normed frequencies (number of errors/ total number of words * 1000 ) of errors. ${ }^{*} p<.05$; : Treatment $1=$ pretest, Treatment $2=$ posttest, Treatment $3=$ delayed posttest.

Concerning the changes of the error rates in the content-only feedback (FC) group in terms of the three treatments, Table 6 shows that there was no statistical significance found from the pretest to posttest ( $t=.95,34 d f, p=.35$, $p>.05)$ and from the posttest to delayed posttest $(t=1.54,34 d f, p=.13, p>.05)$. However, a significant decrease did occur in the content-only feedback group from the pretest to delayed posttest $(t=2.15,34 d f, p=.04, p<.05)$. Although the effect size was small (Cohen's $d=.22$ ), this implies as well that a significant effect of time existed on content feedback in students' performance on writing.

Table 6. Paired Samples T-Test for Feedback in FC Group in the Pretest, Posttest, and Delayed-posttest $(\mathrm{n}=35)^{\mathrm{a}}$

\begin{tabular}{ccccccccc}
\hline Treatment & $M$ & $S D$ & $\begin{array}{c}\text { 95\% Confidence Interval of } \\
\text { the Difference }\end{array}$ & $t$ & $d f$ & $\begin{array}{c}\text { Sig. } \\
\text { (2-tailed) }\end{array}$ & Cohen's $d$ \\
\cline { 3 - 9 } & & \multicolumn{2}{c}{ Lower } & Upper & & & \\
\hline $1-2$ & 2.24 & 13.93 & -2.54 & 7.03 & .95 & 34 & .35 & .09 \\
$2-3$ & 3.27 & 12.59 & -1.05 & 7.60 & 1.54 & 34 & .13 & .15 \\
$1-3$ & 5.51 & 15.19 & .30 & 10.673 & $2.15^{*}$ & 34 & $.04^{*}$ & .22 \\
\hline
\end{tabular}

Note. ${ }^{\text {a: }}$ statistics are calculated based on normed frequencies (number of errors/ total number of words $* 1000$ ) of errors. ${ }^{*} p<.05$; ${ }^{\mathrm{b}}$ : Treatment $1=$ pretest, Treatment $2=$ posttest, Treatment $3=$ delayed posttest. 
One-way ANOVA was calculated to see if the three groups were significantly different in the pretest, posttest and delayed-posttest. Table 7 above demonstrates the results of the ANOVA for different types of feedback by treatment group. As can be seen, there was no statistical significance for group effect obtained across the three tests. Thus, the null hypothesis of no group differences was not rejected at this point. This also indicates that the Indirect $C F$ and Direct CF group which received different types of corrective feedback did not outperform the FC group which received content feedback in their performance on writing accuracy.

Table 7. ANOVA Summary Table of the Overall Errors by Group in the Pretest, Posttest, and Delayed-posttest $(\mathrm{n}=35)^{\mathrm{a}}$

\begin{tabular}{llccccc}
\hline Treatment & Source & SS & df & MS & F & Sig. \\
\hline Pretest & Between groups & 984.63 & 2 & 492.31 & 2.96 & .05 \\
& Within Groups & 16992.67 & 102 & 166.60 & & \\
& Total & 17977.29 & 104 & & & \\
& & & & & & \\
Posttest & Between groups & 135.442 & 2 & 67.72 & 1.01 & .37 \\
& Within Groups & 6854.52 & 102 & 67.20 & & \\
& Total & 6989.96 & 104 & & & .89 \\
\multirow{2}{*}{$\begin{array}{l}\text { Delayed } \\
\text { posttest }\end{array}$} & Between groups & 16.84 & 2 & 8.42 & .12 & \\
& Within Groups & 7215.57 & 102 & 70.74 & &
\end{tabular}

Note. ${ }^{\text {a }}$ : statistics are conducted based on normed frequencies (number of errors/ total number of words * 1000) of errors. ${ }^{*} p<.05$.

\subsection{RQ3: Students' Expectations and Preferences for the Feedback on Their Writing}

Similar to previous findings (Ferris, 2010; Mustafa, 2012; McMartin-Miller, 2014), students in the current study revealed a great concern about accurate writing and cared about having their written errors corrected. Students from all groups highly appreciated the type of feedback received from the researcher and were very positive about the benefits of corrective feedback.

As shown in Table 8 and Table 9, a significant correlation was found between students' responses to Q4 and their error rates in the posttest. The relationship between students' responses to Q5 and error reduction from the pretest to the delayed posttest was found to be significant as well. The results indicate that the more students worried about making mistakes in writing, the more errors students were likely to make; and accordingly the less confident students felt about their English ability, the more errors students made. When taking a further look at relationships among the other items in Questionnaire 1 and 2, significant correlations were not found.

Table 8. Correlation between the Total Number of Errors in the Three Tests and Students' Attitudes in Questionnaire 1

\begin{tabular}{llllll}
\hline \multicolumn{1}{c}{ Sig. } & Q1 & Q2 & Q3 & Q4 & Q5 \\
\hline Pretest & .75 & .86 & .38 & .31 & .21 \\
Posttest & .87 & .88 & .78 & $.02 * a$ & .34 \\
Delayed posttest & .99 & .20 & .48 & .87 & .21
\end{tabular}

Note. ${ }^{\text {a: }}$ Pearson correlation $=-.38$. 
Table 9. Correlation between Error Reduction across the Three Tests and Students' Attitudes in Questionnaire 1

\begin{tabular}{llllll}
\hline \multicolumn{1}{c}{ Sig. } & Q1 & Q2 & Q3 & Q4 & Q5 \\
\hline Pre_Post & .65 & .76 & .23 & 1.00 & .35 \\
Post_Delayed & .92 & .20 & .67 & .07 & .07 \\
Pre_Delayed & .75 & .59 & .19 & .27 & $.04 *$ a \\
\hline
\end{tabular}

Note. ${ }^{\text {a: }}$ Pearson correlation $=-.36$.

\section{Discussion}

There are some possible explanations for the absence of significant differences among the three groups. First, EFL learners' advanced English proficiency can be accounted for as a factor that potentially affects their production of accurate writing. Even though students from the three groups were identical in their overall English proficiency based on their scores in the college entrance exam, students were not actually equal in their initial writing proficiency as they performed differently in accuracy in the pretest. The control (FC) group exhibited more accurate performance in the pretest. However, in general all three groups wrote fairly accurate essays across the treatments. In this case, it can be assumed that because of their advanced English proficiency whether or not students received feedback and grammar correction on their first writing did not seem to influence their performance on the subsequent writing assignments.

The second possible explanation to why CF did not show any group effect on student writing accuracy might be because of the insufficient duration of the treatment. The research lasted for only ten weeks, which was a short period of time. A two-month experiment may not be long enough to reveal the influence of CF on student writing accuracy. It was even impractical to expect a surprising significant group difference in error rates over only ten weeks especially given students' fairly high accuracy at the beginning of the treatment.

It is also possible that some students may not benefit from CF because of their attitudes in dealing with CF in their self-correction process. First, students may not be willing to deal with or not interested in understanding how the CF could work and help them improve their writing. Second, students may not understand the feedback, which may raise a certain level of anxiety and discouragement, consequently leading to their incapability of fixing the errors.

While this study did not reveal statistically significant group differences between the two CF groups and the FC group on overall error reduction, we doubt to conclude that the improved accuracy is attributed to CF because the control (FC) group that did not receive $\mathrm{CF}$ also improved. Therefore, although impressionistically students from the two $\mathrm{CF}$ groups (i.e., indirect $\mathrm{CF}$ and direct $\mathrm{CF}$ ) appeared to benefit from the treatment in some way above and beyond what would have occurred in a non-CF treatment as revealed in the statically significant time effect, the results did not indicate which type of CF leads to greater gains or a higher level of correction in either short-term revision or long-term written accuracy. This is supported by Kang and Han's (2015) meta-analysis, which did not show any clear-cut differences between the indirect and direct CF on their efficacy in writing.

For perceived value of the corrective feedback, all participants confirmed the importance and value of CF to improve student writing accuracy and general English ability, and showed favorable attitudes towards CF in language learning. Students also expressed that they did not feel being discouraged by CF, and they would like to apply the corrections to their future writing.

Finally, I would argue that although the study did not show a statistically significant positive effect of CF on student writing accuracy, we cannot conclude that CF is completely ineffective or even harmful; we cannot deny the potential benefit of CF, either. The application of CF could be potentially influenced, either in a positive or negative means, by internal and external factors such as student English proficiency, research design, the length of experiment, instructional context, etc.

\section{Pedagogical Recommendations for EFL Teachers}

The current research provides a practical perspective on how language teachers need to be more aware of the challenges and benefits of using corrective feedback during grammar learning. In particular, this study informs teachers of English in international settings (e.g., China) how to better develop materials, activities and tasks that are applicable for L2 students in form-focused instruction. The study also shows how language teaching should lessen students' difficulties instead of posing more challenges. EFL Teachers need to consider when and how to provide 
appropriate corrective feedback and to incorporate grammar learning materials that take into account students' individual differences, such as their English proficiency level, motivation, and attitudes. Factors that contribute to influencing L2 learners' writing accuracy cannot be intuitively discerned and must be identified by L2 instructors.

Though some individual students dislike being corrected and think judgment of errors might be too tough on them, the occurrence of errors will not stop happening if students do not give enough consideration to error correction. It is also true that although L2 learners may be able to generate a great idea in writing tasks, readers could still have a difficult time understanding the texts if they are filled with errors. Therefore, it is important for teachers to help students understand how feedback is intended to affect their L2 learning and why it is given in the way it is. Otherwise, students might not be able to interpret how beneficial feedback can be.

\subsection{Considering Learner Factors}

Many researchers have proposed suggestions on pedagogical practices in L2 classrooms in order to limit the negative effect of certain kinds of CF for L2 learners, such as students' increased anxiety when being corrected. When providing corrective feedback, it is important for EFL teachers to take into consideration a wide range of learner factors so that teachers can obtain a better understanding of the origins of their students' errors and provide efficient and appropriate feedback that help students progress in their language growth. In particular, language teachers should consider students' perspectives, sensitivity, personality, expectations, preferences, and affective needs when providing corrective feedback. Teachers should not impose their own assumptions on students and should deal with conflicts between students' beliefs and instructional practices. In addition, since many studies suggested that the teacher feedback had a great potential for miscommunication and misunderstanding, it is recommended that teachers build up a connection between students' expectations and teachers' beliefs by having dialogues and interactions with students to negotiate the aims and expectations of feedback.

\subsection{Developing Self-Correction Strategies}

According to SLA and L2 writing literature, teachers are responsible for helping L2 learners recognize errors, develop self-revision skills, and to make the best use of error feedback for further language tasks. To be more specific, different error types need to receive various treatments from teachers, such as complex sentence structures, word choice, and other idiosyncratic uses of language forms. It is necessary for EFL teachers to carefully identify and respond to different types of errors by providing detailed grammar explanations and to teach students the correct way of responding to errors. In other words, teacher should explicit train students for self-correction strategies in class. For instance, the teacher can have their students engage in group work to identify and correct errors that commonly occur in their peers' writing. Peer correction can consolidate students' grammar knowledge and make the knowledge explicit to benefit each other. This could be a productive way as well of helping students explain to themselves the errors and then to find the correct answers.

\subsection{Integrating Grammar Instruction}

As explicit instructions on grammar are crucial in language classrooms, effective and efficient grammar instruction needs to be integrated into the correction process. Especially for Asian students, grammar instruction has a significant impact on language learning because of their language proficiency and previous learning experience in countries where English teaching and learning involves strongly stressed explicit grammar instruction. Schulz (2001) provided data that showed students from different cultures shared the view that the interaction between grammar instruction and feedback plays a positive role in language learning. In this case, we do not deny that learners could automatically acquire and learn language as long as they are exposed to a foreign language environment from which they receive rich and comprehensible input. A formal Form Focused Instruction (FFI) could help and foster EFL learners' ultimate mastery of a foreign language.

\section{References}

Biber, D., Johansson, S., Leech, G., Conrad, S., \& Finegan, E. (1999). The Longman grammar of spoken and written English. London: Longman.

Bitchener, J. (2008). Evidence in support of written corrective feedback. Journal of Second Language Writing, 12, 102-118. https://doi.org/10.1016/j.jslw.2007.11.004

Bitchener, J., \& Ferris, D. (2011). Written Corrective Feedback in Second Language Acquisition and Writing. New York, NY: Routledge.

Bitchener, J., \& Knoch, U. (2008). The value of written corrective feedback for migrant and international students. 
Language Teaching Research, 12, 409-431. https://doi.org/10.1177/1362168808089924

Bitchener, J., \& Knoch, U. (2009). The contribution of written corrective feedback to language development: Aten month investigation. Applied Linguistics, 31,193-214. https://doi.org/10.1093/applin/amp016

Bitchener, J., \& Knoch, U. (2010). Raising the linguistic accuracy level of advanced L2 writers with written corrective feedback. Journal of Second Language Writing, 19, 207-217. https://doi.org/10.1016/j.jslw.2010.10.002

Bruton, A. (2009a). Designing research into the effect of grammar correction in L2 writing: not so straightforward. Journal of Second Language Writing, 18, 136-40. https://doi.org/10.1016/j.jslw.2009.02.005

Bruton, A. (2009b). Improving accuracy is not the only reason for writing, and even if it were... System, 37, 600-613. https://doi.org/10.1016/j.system.2009.09.005

Chandler, J. (2003). The efficacy of various kinds of error feedback for improvement in the accuracy and fluency of L2 student writing. Journals of Second Language Writing, 12, 267-296. https://doi.org/10.1016/S1060-3743(03)00038-9

Ellis, R., Sheen, Y., Murakami, M., \& Takashima, H. (2008). The effects of focused and unfocused written corrective feedback in an English as a foreign language context. System, 36, 353-371. https://doi.org/10.1016/j.system.2008.02.001

Ferris, D. (1999). The case for grammar correction in L2 writing classes: A response to Truscott (1996). Journal of Second Language Writing, 8, 1-11. https://doi.org/10.1016/S1060-3743(99)80110-6

Ferris, D. (2002). Treatment of Errors in Second Language Student Writing. Ann Arbor, MI: University of Michigan Press.

Ferris, D. R. (2004). The "grammar correction" debate in L2 writing: Where are we, and where do we go from here? Journal of Second Language Writing, 13, 49-62. https://doi.org/10.1016/j.jslw.2004.04.005

Ferris, D. R. (2010). Second language writing research and written corrective feedback in SLA. Studies in Second Language Acquisition, 32, 181-201. https://doi.org/10.1017/S0272263109990490

Ferris, D. R., \& Roberts. B. (2001). Error feedback in L2 writing classes: How explicit does it need to be? Journals of Second Language Writing, 10, 161-84. https://doi.org/10.1016/S1060-3743(01)00039-X

Ferris, S., Liu, H, Sinba, A., \& M. Senna. (2013). Written corrective feedback for individual L2 writers. Journal of Second Language Writing, 22, 307-329. https://doi.org/10.1016/j.jslw.2012.09.009

Hyland, F. (2003). Focus on form: Student engagement with teacher feedback. System, 31, 217-30. https://doi.org/10.1016/S0346-251X(03)00021-6

Jwenigan, J., \& Mihan, F. (2008). Error treatment preferences of adult Intensivee English Program students: Does proficiency matter? The CATESOL Journal, 20.

Kang, E., \& Han, Z. (2015). The efficacy of written corrective feedback in improving L2 written accuracy: A meta-analysis. The Modern Language Journal, 99, 1-18. https://doi.org/10.1111/modl.12189

Kepner, C. (1991). An experiment in the relationship of types of written feedback to the development of second language writing skills. Modern Language Journal, 75, 305-313. https://doi.org/10.1111/j.1540-4781.1991.tb05359.x

Kranshen, S. (1985). The input hypothesis: Issues and implication. Oxford: Pergamon Press.

Krashen, S. (1981). Second Language Acquisition and Second Language Learning. Oxford: Oxford University Press.

Krashen, S. (1982). Principles and Practice in Second Language Acquisition. New York: Pergamon Press.

Lee, Icy. (2003). L2 writing teachers' perspectives, practices and problems regarding error feedback. Assessing Writing, 8, 216-37. https://doi.org/10.1016/j.asw.2003.08.002

Lee, Icy. (2005). Error correction in L2 secondary writing classroom: The case of Hong Kong. Journal of Second Language Writing, 13, 285-312. https://doi.org/10.1016/j.jslw.2004.08.001

Lee, Icy. (2008). Student reactions to teacher feedback in two Hong Kong secondary classrooms. Journal of Second Language Writing, 17, 144-164. https://doi.org/10.1016/j.jslw.2007.12.001

Leki, I. (1991). The preferences of ESL students for error correction in college-level writing classes. Foreign Language 
Annals, 24, 203-218. https://doi.org/10.1111/j.1944-9720.1991.tb00464.x

Liu, M., \& Braine, G. (2005). Cohesive features in argumentative writing produced by Chinese undergraduates. System, 33, 623-36. https://doi.org/10.1016/j.system.2005.02.002

McMartin-Miller, C. (2014). How much feedback is enough?: Instructor practices and student attitudes toward error treatment in second language writing. Assessing Writing, 19, 24-35. https://doi.org/10.1016/j.asw.2013.11.003

Mustafa, F. (2012). Feedback on the feedback: Sociocultural interpretation of Saudi ESL learners' opinions about writing feedback. English Language Teaching, 5, 3. https://doi.org/10.5539/elt.v5n3p3

Polio, C. (2012). The relevance of second language acquisition theory to the written error correction debate. Journal of Second Language Writing, 21, 375-389. https://doi.org/10.1016/j.jslw.2012.09.004

Robb, T., Ross, S., \& Shortreed, I. (1986). Salience of feedback on error and its effect on EFL writing quality. TESOL Quarterly, 20, 83-95. https://doi.org/10.2307/3586390

Russell, J., \& Spada, N. (2006). The effectiveness of corrective feedback for the acquisition of L2 grammar: A meta-analysis of the research. In J. Norris \& L. Ortega (Eds.), Synthesizing Research on Language Learning and Teaching (pp.133-164). Amsterdam: Benjamins.

Schulz, R. (2001). Cultural differences in student and teacher perceptions concerning the role of grammar instruction and corrective feedback: USA-Colombia. The Modern Language Journal, 85, 244-58. https://doi.org/10.1111/0026-7902.00107

Sheen, Y., Wright, D., \& A. Moldawa. (2009). Differential effects of focused an unfocused written correction on the accurate use of grammatical forms by adult ESL leaners. System, 37, 556-569. https://doi.org/10.1016/j.system.2009.09.002

Shintani, N., Ellis, R., \& Suzuki, W. (2014). Effects of written feedback and revision on learners' accuracy in using two English grammatical structures. Language Learning, 64, 103-131. https://doi.org/10.1111/lang.12029

Truscott, J. (1996). Review Article: The case against grammar correction in L2 writing classes. Language Learning, 46, 327-69. https://doi.org/10.1111/j.1467-1770.1996.tb01238.x

Truscott, J. (1999). The case for "The case against grammar correction in L2 writing classes": A response to Ferris. Journal of Second Language Writing, 8, 111-122. https://doi.org/10.1016/S1060-3743(99)80124-6

Truscott, J. (2004). Evidence and conjecture on the effects of correction: A response to Chandler. Journal of Second Language Writing, 13, 337-343. https://doi.org/10.1016/j.jslw.2004.05.002

Truscott, J. (2007). The effect of error correction on learners' ability to write accurately. Journal of Second Language Writing, 16, 255-72. https://doi.org/10.1016/j.jslw.2007.06.003

Truscott, J., \& Hsu, A. (2008). Error correction, revision, and learning. Journal of Second Language Writing, 17, 292-305. https://doi.org/10.1016/j.jslw.2008.05.003

Van Beunnigen, C., De Jong, N., \& F. Kuiken. (2012). Evidence on the effectiveness of comprehensive error correction in second language writing. Language Learning, 62, 1-41. https://doi.org/10.1111/j.1467-9922.2011.00674.x

Vyatkina, N. (2011). Writing instruction and policies for written corrective feedback in the basic language sequence. L2 Journal, 3, 63-92.

Wang, Z. (2011). Chinese high school students' L2 writing instruction: Implications for EFL writing in college: A qualitative study. Chinese English Language Education Association. Retrieved from http://www.celea.org.cn/pastversion/lw/pdf/wangzhaohui 


\section{Appendix A: Questionnaire 1}

1. In English classes you have taken before, have you ever learned any English grammar rules?

$$
\text { Yes, a lot Yes, but few No }
$$

2. Have you ever received feedback from teachers?

$$
\text { Yes, a lot Yes, but few No }
$$

3. Do you think teacher feedback is helpful?

$$
\text { Yes, very helpful Yes, but not much No }
$$

4. Do you worry about making mistakes in writing or your language class?
Yes, a lot
Yes, but few
No

5. How do you feel about your English language use, especially grammar, in writing?
Very good
Good
bad

Appendix B. Questionnaire 2

1. What is the best way for your English teacher to give feedback on your writing?

Feedback on grammar feedback on content feedback on organization none of these

2. What is the best way for your English teacher to give feedback about your grammatical errors in your writing?

Direct correction underline or circle description and explanation none of these

3. Why type of corrective feedback do you like most?

Direct correction underline or circle description and explanation none of these

4. Do you like the current type of corrective feedback you received from the researcher?

Very much

mostly

a little

not at all

5. Do you understand the type of corrective feedback you received from the researcher?

Very much

mostly

a little

not at all

6. Do you feel discouraged about the correction?

Very much

mostly

a little

not at all

7. Do you think you will apply the correction to your future writing?

Very much

mostly

a little

not at all 